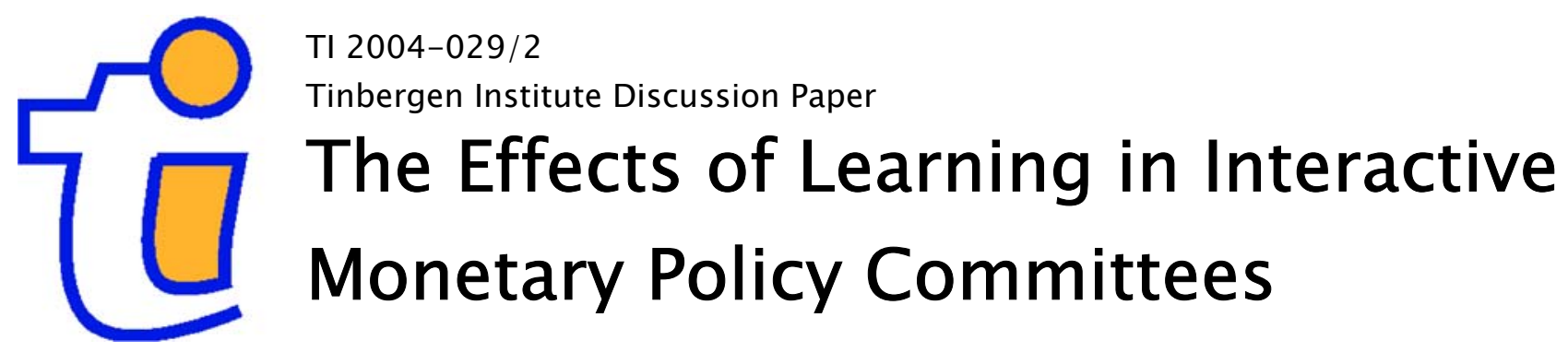

Jan Marc Berk1,3,4

Beata K. Bierut2,3,4

1 Faculty of Economics and Business Administration, Vrije Universiteit Amsterdam,

2 Faculty of Economics, Erasmus Universiteit Rotterdam,

3 Tinbergen Institute,

${ }_{4}$ De Nederlandsche Bank, Amsterdam. 


\section{Tinbergen Institute}

The Tinbergen Institute is the institute for economic research of the Erasmus Universiteit Rotterdam, Universiteit van Amsterdam, and Vrije Universiteit Amsterdam.

Tinbergen Institute Amsterdam

Roetersstraat 31

1018 WB Amsterdam

The Netherlands

Tel.: $\quad+31(0) 205513500$

Fax: $\quad+31(0) 205513555$

Tinbergen Institute Rotterdam

Burg. Oudlaan 50

3062 PA Rotterdam

The Netherlands

Tel.: $\quad+31(0) 104088900$

Fax: $\quad+31(0) 104089031$

Please send questions and/or remarks of nonscientific nature to driessen@tinbergen.nl.

Most TI discussion papers can be downloaded at http://www.tinbergen.nl. 


\title{
The effects of learning in interactive monetary policy committees
}

\author{
Jan Marc Berk*and Beata K. Bierut ${ }^{\ddagger}$
}

March 1, 2004

\begin{abstract}
We develop a theoretical framework for studying the effects of interaction on the quality of decision-making by monetary policy committees. We show that interaction, ie increasing one's expertise through an exchange of views, is most likely not to result in interdependent voting behaviour. Therefore, and in contrast to earlier literature, we find that interaction is beneficial for the collective outcome.
\end{abstract}

Jel Codes: E52, E58, D83, D71

Key Words: Monetary policy, interest rates, learning

\section{Introduction}

The primary goal of this paper is to explore the economic implications of a simple decision theoretic approach to group decision making. Compared to classical social theoretic approaches (see, for example, Arrow, 1963; Sen, 1970, 1977), in which collective action is based on diverse preferences of the individuals in the group, our starting point is the premise that group decision making should be based on common preferences of the decision makers and on their decisional competence. Moreover, we restrict our analysis to dichotomous choice situations. That is, we assume that individual members of a group share a common interest, they are all involved in the same single task

${ }^{*}$ De Nederlandsche Bank and Tinbergen Institute, the Netherlands.

${ }^{\dagger}$ De Nederlandsche Bank, Erasmus University Rotterdam and Tinbergen Institute, the Netherlands. Corresponding author. E-mail: B.K.Bierut@dnb.nl.

‡The authors thank Ellen Meade, Job Swank, Otto Swank, Bauke Visser, and Bryan Chapple for their invaluable help and comments. The views expressed are those of the authors and need not represent the ones of the institutions affiliated. 
(in which they face the same binary set of possible actions), but they might possess different decisional skills. The latter diversity may partly reflect the different signals or information available to the individuals concerned. However, it is also possible that, although sharing identical information, they will make different choices due to the diversity in their talents to absorb, process and translate the information into the desirable decision. Consider for example a group of central bankers, comprising a monetary policy committee (MPC). Despite being exposed to the same information regarding the state of the economy, members might reach different conclusions regarding the appropriate interest rate due to their personal interpretation of the information and the heterogeneity of their capabilities. Assuming that members share the same goal, i.e. achieve a certain objective of monetary policy (price stability, for example), does not seem overly restrictive. The decision to be taken by a MPC can be naturally interpreted as being binary, i.e. whether to change interest rates or not. The direction of a change seems far less controversial, as it usually can be inferred by the recent history of the economy.

Our framework allows us to provide insights into the resolution of numerous realistic issues. Prominent among those features monetary policy making by a committee. A MPC can be interpreted as an organization which produces as its main output a decision on interest rates. This collective decision is the result of a complex combination of inputs such as the number and quality of members, and the time required for decision making. We are in particular interested in the impact of the 'technology' relating the inputs to the output. In this paper, we will focus on three crucial aspects of this technology: interdependence among individual members due to learning, informational asymmetries between members and the formation of coalitions within the MPC.

This focus is motivated by casual empirical observation. Some well-known central banks organize their monetary policy decision making through committees. ${ }^{1}$ As noted by others (Goodfriend, 1999; De Nederlandsche Bank, 2000), an important characteristic of MPC's is that members communicate with each other, convince each other and may learn from each other. Moreover, two of the most influential central banks, the US Federal Reserve and the European System of Central Banks, have a structure characterized by a main office in a central location (the 'hub') with additional regional offices throughout the currency area (the 'spokes'). MPC members from the hub (for example the Board of Governors in the US or the ECB Executive Board in Europe) have relatively more intensive contacts among each other than

\footnotetext{
${ }^{1}$ As noted by, inter alia, Blinder (1998), this could have implications for the conduct of policy.
} 
the members from the spokes. This is due to the fact that the former are geographically concentrated (i.e. located in the same building) and that they have to meet regularly anyway to decide on other issues. It is not difficult to imagine that during these meetings, they 'pre-empt' on interest rate discussions forthcoming in the MPC, implying an informal prior board meeting which might lead to a coalition, in the form of a common prior position on interest rates, within the MPC. Finally, both in the US and in Europe, the hub is entrusted with the preparation of the MPC meetings, which might give them an informational advantage, implying informational asymmetries.

We show that this technology of a MPC has important consequences for the quality of its decisions, even if committee members share a common goal. We consider relaxing the assumption of preference differences an important addition to the existing literature (see, for example, von Hagen and Süppel, 1994; Hefeker, 2003; Sibert, 2003). A second contribution stems from the fact that we do not impose a priori that interaction implies interdependent voting (Nitzan and Paroush, 1985; Ladha, 1992; Ladha, 1995) but instead determine the conditions under which interdependent voting emerges. A final contribution stems from the introduction of time into group decision making, which makes transparent the trade-off between the optimal size of the committee and the optimal amount of time it requires to take a collective decision.

The structure of the paper is as follows. We start, in section two, by describing the effects of time on the expertise of committee members, i.e. the learning process, followed by specifying several decision-making processes of interest (section three). In section four we turn to an investigation of the quality of decision-making under several decision-making scenarios and committee members' characteristics. Section five discusses the optimal size and decision time of the committee. Section six concludes.

To preview our findings, we show that the well-known result that interaction is detrimental to the collective outcome (due to an inefficient use of information) requires very restrictive and unrealistic assumptions. In a less restrictive setting, which we consider more realistic, members increase their expertise through an exchange of views in the committee meeting, but base their vote on their own opinion. This will improve the collective outcome. Moreover, a committee designer faces a certain degree of flexibility between committee size and the amount of time available to reach a collective decision, depending on the magnitude of costs involved. A smaller MPC may do as well as a larger one, provided that it will receive more time for reaching a decision. 


\section{Learning}

Assume an economy which can be in either of two states of the world: economic conditions are such that a change in policy rates is required (state $a$ ) or not (state $b$ ). MPC members $i=1, \ldots, n$ have to assess the unobservable state using available information. Assume that the ability to assess the state of the economy correctly is specific for each individual: the probability that an individual takes the correct decision based on his knowledge ${ }^{2}$ differs among committee members: $P_{i}($ vote $A \mid a)=P_{i}($ vote $B \mid b)=q_{i}$ and consequently $P_{i}($ vote $B \mid a)=P_{i}($ vote $A \mid b)=1-q_{i} .{ }^{3}$ The differences in individual abilities are not unbounded, however, as expertise is an important selection criterion for committee membership. The Maastricht Treaty is a case in point as it requires (in Article 11) ECB Board members to be endowed with "professional experience in monetary or banking matters". We formalize this legal requirement by assuming that individual inherent skills $q_{i}$ represent independent draws from a single distribution with mean $q$.

A key characteristic of committee decision-making (Goodfriend, 1999) is that it involves an (informative) exchange of views regarding the current state of the economy, as well as its likely future development (over a horizon relevant to the monetary transmission mechanism). These discussions allow committee members to expand their private knowledge, gain new insights, get new ideas, or improve their expertise in any other way. We label this process as 'learning' ${ }^{4}$ Following experimental evidence (Lombardelli et al, 2002) we assume that learning can be captured by two effects:

1. catching-up: less-skilled committee members update their knowledge learning from their more-skilled colleagues. Members' skills should therefore converge, although not necessarily perfectly. This is because sharing expertise requires time, which in our case is scarce. As a matter of fact, we assume that the total amount of time available to the committee to reach a collective decision is fixed. ${ }^{5}$ As a result individ-

\footnotetext{
${ }^{2}$ I.e. the probability of supporting a change in interest rates (decision $A$ ) in state $a$ and opposing it (i.e. voting for decision $B$ ) in state $b$.

${ }^{3}$ We assume that individual expertise $q_{i}$ ranges between 0.5 and $\bar{q}_{i}$ for all $i=1, \ldots, n$, where $\bar{q}_{i}$ is the upper limit on individual skills $\left(\bar{q}_{i} \leq 1\right)$. For a discussion of the assumption of $q_{i}>0.5$, see Ladha (1992). Note that this assumption implies that each member receives enough but incomplete information about the true state of the economy. If $q_{i} \leq 0.5$, the decision could be taken by tossing a coin.

${ }^{4}$ Note that learning presupposes interaction; without interaction each committee member decides based only on his own views.

${ }^{5}$ This assumption is easily justified, as the duration of both the meetings of the FOMC of the FED and the Governing Council of the ECB is pre-announced.
} 
ual learned skills (denoted as $\widetilde{q}_{i}$ ) may still differ when the committee decides on interest rates.

2. knowledge creation: learning is not limited to members with relatively low skills, as during discussions more-skilled committee members may get new insights or ideas and therefore increase their expertise. ${ }^{6}$

Both effects are captured analytically by the functional form: ${ }^{7}$

$$
\widetilde{q}_{i}=\bar{q}_{i}-\left(\bar{q}_{i}-q_{i}\right) \exp \left(-\lambda_{i} T\right)
$$

where $T$ denotes total time available to the committee to take the collective decision ${ }^{8}, \bar{q}_{i}$ is the (exogenous) upper limit on individual skills and $\lambda$ determines the rate of learning (i.e. the slope of the learning curve at time T). ${ }^{9}$ As to the latter, we will focus on the effects of committee characteristics ('technology') on the learning process, and assume that the rate of learning is positively related to the relative number of more-skilled group members:

$$
\lambda_{i}=\lambda_{i}(\omega), \lambda_{i}^{\prime}>0
$$

where $\omega$ is the share of more-skilled members in the group, $0 \leq \omega \leq 1$. $^{10}$

The abovementioned learning effects imply that there are two learning curves, since the upper limit on learned skills is different for the more- and less-skilled committee members. Knowledge creation implies that with time the expertise of the more-skilled members approaches an exogenously determined upper limit of individual accuracy: ${ }^{11}$

$$
\widetilde{q}_{i, i \in M S}=0.9-\left(0.9-q_{i}\right) \exp \left(-\lambda_{i} T\right)
$$

\footnotetext{
${ }^{6}$ Naturally, if the skills are a priori homogeneous, only the second effect occurs.

${ }^{7}$ See e.g. Goldstein et al. (1993).

${ }^{8}$ If $T=0$ there is no interaction (and learning): the committee assembles and members immediately and simultaneously take a vote on interest rates.

${ }^{9} \lambda_{i}$ governs the speed of reducing the competence gap $\left(\bar{q}_{i}-\widetilde{q}_{i}\right): \frac{\partial\left(\bar{q}_{i}-\widetilde{q}_{i}\right)}{\partial T}=-\frac{\partial \widetilde{q}_{i}}{\partial T}=$ $-\lambda_{i}\left(\bar{q}_{i}-\widetilde{q}_{i}\right) \leq 0$. Therefore if $\lambda_{i}$ is large, the learning curve is concave, since the initial reduction in the competence gap is large. If $\lambda_{i}$ is small, the reduction in the competence gap becomes more gradual, and the learning curve is approximately linear. As a result, $\lambda_{i}$ also effects the final competence gap: the larger $\lambda_{i}$, the higher the final competence: $\frac{\partial \widetilde{q}_{i}}{\partial \lambda_{i}}=T\left(\bar{q}_{i}-q_{i}\right) \exp \left(-\lambda_{i} T\right) \geq 0$.

${ }^{10}$ Further in the analysis we will assume the simplest functional form for lambda: $\lambda_{i}=\omega$.

${ }^{11}$ In theory, the maximum limit on any probability is 1 , but we will more modestly assume that the capacity of any individual to judge the state of the world correctly is $90 \%$.
} 
where $M S \subset N$ is the subset of more-skilled committee members. Catchingup means that the expertise of the less-skilled individual approaches the expertise of the more skilled members:

$$
\widetilde{q}_{i, i \in L S}=\widetilde{q}_{i, i \in M S}-\left(\widetilde{q}_{i, i \in M S}-q_{i}\right) \exp \left(-\lambda_{i} T\right)
$$

where $L S \subset N$ is the subset of less-skilled committee members.

It is useful to elaborate somewhat on the economics behind our assumed learning process. Note that we identify heterogenous skills $\widetilde{q}_{i}$, without having to specify the sources of this heterogeneity. The latter may for example result from different models used regarding the functioning of the economy. Alternatively, committee members use identical models but confront them with different data sets. In the latter case, members will be able to derive identical solution paths describing the evolution of the relevant variables. These are of course functions of the structural parameters of the economy. Estimates of these parameters might differ among members, and due to interaction some members will be able to update their parameter estimates based on the information provided by other members. What we then have is a learning process in which committee members update their expectations (in this case, about the current and projected path of key policy variables) based on new information, an interpretation that is consistent with the recently mushrooming literature on learning, see e.g. Evans and Honkapohja (2001). Note, however, that the generality of our framework also allows for alternative interpretations.

\section{Committee decision-making}

The MPC is comprised of members who ex hypothesi share a common goal, i.e. making the correct interest rate decision, which corresponds to imposing reputational concerns on committee members. Throughout the analysis, we consider two cases. In the first, there is only a policy meeting (that is, a meeting of the MPC). Committee members assemble in order to decide on interest rates, and, depending on the time available, they discuss their views or simply take a vote (which is simultaneous). In the second case, a MPC meeting is preceded by an informal prior board meeting in which $m$ out of $n$ (exogenously selected) MPC members ${ }^{12}$ discuss economic conditions. This informal meeting is then followed by a MPC meeting where the interest rate decision is taken, with or without interaction, depending on the time available. This two-stage decision-making process seems especially relevant

\footnotetext{
${ }^{12}$ Throughout the analysis we will assume that $m$ is even and $n$ is odd.
} 
for monetary policy committees in systems of central banks, such as the Fed or the ESCB. There, one could well envisage that the Board of Governors or the Executive Board discuss interest rates prior to the meeting of the FOMC or the Governing Council, respectively (see the introduction).

Besides possible empirical relevance, a two-stage decision-making process is useful for analyzing the incentives individual members have to follow the views of others. The latter may (but, as we shall argue later on, need not) be the result of learning the views of other decision-makers (i.e. interaction). ${ }^{13}$ More specifically, during the informal prior meeting a subset of the committee (i.e. the board) may formulate a common position, which can subsequently be revealed to other members. Non-board committee members interested in attaining the best possible collective outcome then face a choice between following their own views and following the common position of the board. ${ }^{14}$ Note, however, that the interest rate decision formally has to be taken by the whole committee. The board thus has an option (which is not available to the committee) not to take any decision. Our decision rule for the board reflects this endogenous possibility. The informal prior meeting of the board generates one out of three outcomes: a common position for a change in interest rates, a common position against a change or no common position. Notwithstanding the lack of an optimality result (due to Arrow's impossibility theorem), it can be shown (Berk and Bierut, 2003) that this rule is superior to simple majority (by which the board always assumes a common position) in terms of quality of decision-making. A second justification of our assumed rule for the board lies in its real-life relevance. Meade and Sheets (forthcoming) document the existence of dissents among members of the Board in their study of FOMC voting behavior. A priori assuming a common position in the board thus seems at odds with reality. On the other hand, given that we want to investigate the effects of a coalition within the MPC on the quality of the collective decision, we do not want to rule out the possibility of reaching a common position a priori.

\footnotetext{
${ }^{13}$ We therefore do not consider these incentives when the lack of time does not allow for interaction (i.e. if $T=0$ ). In this respect, our approach differs from the existing literature, where following the majority view is analysed in a simultaneous voting game (see e.g. Nitzan and Paroush (1985)).

${ }^{14}$ In order to introduce a similar choice for board members, we assume that their common position may be formed not only when they are actually unanimous. We assume that board members may decide to present a common view on the appropriate interest rates decision also when a certain majority $k_{b}\left(\frac{m}{2}+1 \leq k_{b}<m\right)$ of them supports this decision. In such a case $\frac{m}{2}-1$ board members decide to forego their own opinion.

Assuming that presenting a common position requires unanimity would have two effects: (1) the strategic choice of board members is ruled out, and (2) the dissents among board members would be far more frequent.
} 
The simple diagram below presents the second case. ${ }^{15}$ Note that the setup described above is separate from the issue of learning, which will be taken up in the next section.

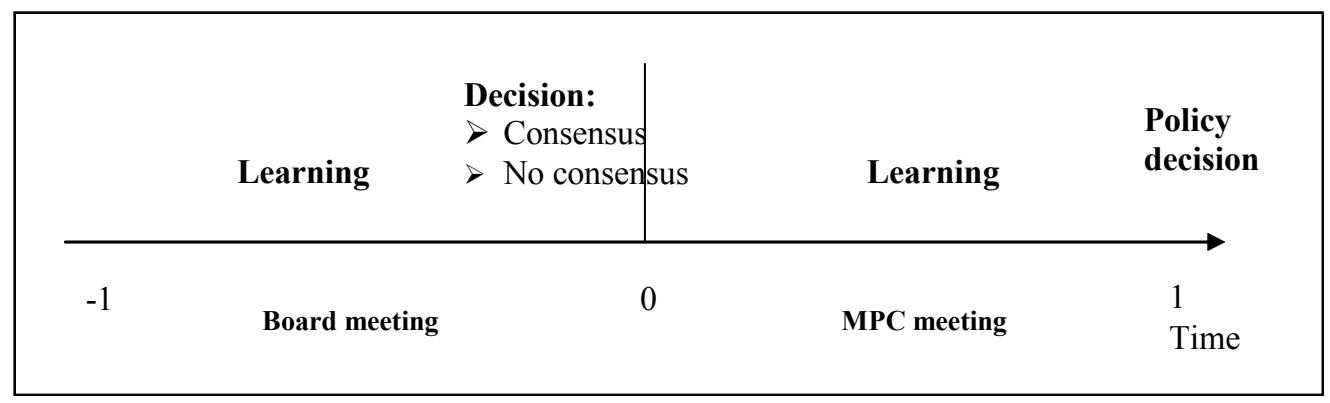

The quality of collective decision-making is measured by the conditional probability that the committee takes the correct decision, i.e. $P(B \mid b)$ (or, equivalently, $P(A \mid a)$ ). When there only is a policy meeting (the first case above) this quality can be calculated as:

$$
P(B \mid b)=\sum_{\substack{S \subset N \\ s \geq \frac{n+1}{2}}} \prod_{i \in S} \widetilde{q}_{i} \prod_{i \notin S}\left(1-\widetilde{q}_{i}\right)
$$

The summation runs over all subsets $S$ of committee members, who vote for the correct decision and whose number $s$ is large enough to pass this decision by simple majority (i.e. $s$ must be at least $\left.\frac{n+1}{2}\right) .{ }^{16}$

The second case is more complicated, as the outcome of the informal prior board meeting has implications for the number of votes casted by nonboard members necessary to pass the correct decision in the policy meeting: if the board does not reach consensus, its members will vote individually on interest rates, ex hypothesi expressing the same opinion as voiced in the board meeting. In this case all committee members vote individually. As a result between $\frac{n+1}{2}-\left(m-k_{b}+1\right)$ and $\frac{n+1}{2}-\left(k_{b}-1\right)$ votes of non-board MPC members are required to pass either decision. Therefore the conditional probability that the committee adopts the correct decision in this case is given by:

$$
P_{1}(B \mid b)=\sum_{\substack{S_{b} \subset M \\ m-k_{b}+1 \\ \leq s_{b} \leq k_{b}-1}}\left(\prod_{i \in S_{b}} \widetilde{q}_{i} \prod_{i \notin S_{b}}\left(1-\widetilde{q}_{i}\right) \sum_{\substack{S \subset N-M \\ s \geq \frac{n+1}{2}-s_{b}}} \prod_{i \in S} \widetilde{q}_{i} \prod_{i \notin S}\left(1-\widetilde{q}_{i}\right)\right)
$$

\footnotetext{
${ }^{15}$ We assume that the policy meeting which must result in the interest rate decision begins at time $T=0$ and lasts until $T=1$. The scale to the left from point zero measures the informal prior meeting of board members.

${ }^{16}$ For a study of alternative voting rules, see Berk and Bierut (2003).
} 
The sums are taken first over all subsets $S_{b}$ of board members voting individually for the correct decision, i.e. such that the number of board members in $S_{b}$ (denoted by $s_{b}$ ) is between $m-k_{b}+1$ and $k_{b}-1$, and then over all subsets $S$ of non-board members, who also vote correctly and whose number $s$ is large enough to pass this decision by simple majority, i.e. $s$ must be at least $\frac{n+1}{2}-s_{b}$.

Alternatively, if the informal prior board meeting ends in a common position, obtaining a majority in the policy meeting for the decision supported by the board obviously requires less votes of other MPC members. More specifically, it requires only $\frac{n+1}{2}-m$ out of $n-m$ votes. Obtaining majority for the other alternative requires $\frac{n+1}{2}$ out of $n-m$ votes. Therefore, if the board has adopted a common position favouring the wrong alternative $(A)$, the conditional probability that the policy meeting ends with the correct decision is given by:

$$
P_{2}(B \mid b)=\sum_{\substack{S_{b} \subset M \\ s_{b} \geq k_{b}}} \prod_{i \in S_{b}}\left(1-\widetilde{q}_{i}\right) \prod_{i \notin S_{b}} \widetilde{q}_{i}\left(\sum_{\substack{S \subset N-M \\ s \geq \frac{n+1}{2}}} \prod_{i \in S} \widetilde{q}_{i} \prod_{i \notin S}\left(1-\widetilde{q}_{i}\right)\right)
$$

$S_{b}$ now denotes all subsets of board members voting incorrectly, which have majority in the board and therefore impose consensus for the wrong alternative. $S$ denotes all subsets of non-board members voting correctly and exceeding the required majority $\frac{n+1}{2}$.

Similarly, if the board has adopted a common position in favor of the correct alternative $(B)$ :

$$
P_{3}(B \mid b)=\sum_{\substack{S_{b} \subset M \\ s_{b} \geq k_{b}}} \prod_{i \in S_{b}} \widetilde{q}_{i} \prod_{i \notin S_{b}}\left(1-\widetilde{q}_{i}\right)\left(\sum_{\substack{S \subset N-M \\ s \geq \frac{n+1}{2}-m}} \prod_{i \in S} \widetilde{q}_{i} \prod_{i \notin S}\left(1-\widetilde{q}_{i}\right)\right)
$$

Again subsets $S_{b}$ comprise board members, who vote correctly and have majority in the board. $S$ denotes subsets of non-board members, whose number is large enough to obtain the majority in the committee, i.e. such that $s \geq \frac{n+1}{2}-m .^{17}$

If the common position reached by the board is followed by other MPC members, the board effectively determines the interest rate. In particular, if

\footnotetext{
${ }^{17}$ Obviously, $P(B \cap C B \mid b)$ is larger than $P(B \cap C A \mid b)$, since for $\widetilde{q}_{i}>0.5$, it is true that: (1) all committee members are more likely to be right and therefore the board is more likely to obtain the majority for the correct decision, and (2) in this case the required number of non-board committee members supporting the correct decision may be smaller than the simple majority.
} 
the common position of the board is wrong, it becomes impossible to pass the correct decision. ${ }^{18}$

Given these expressions, we are able to calculate the quality of the collective decision taken by the MPC, if the policy meeting is preceded by an informal prior meeting of the board: ${ }^{19}$

$$
P(B \mid b)=P_{1}(B \mid b)+P_{2}(B \mid b)+P_{3}(B \mid b)
$$

The expressions above can be somewhat simplified. Given that the objective of this paper is to investigate group decision-making, we follow the literature (see, for example, Owen et al., 1989, and Grofman et al., 1982) by focusing on (sub)group instead of individual characteristics. A natural summary statistic in this respect is that of a (sub)group mean competence:

$$
\begin{aligned}
\widetilde{q}_{M S} & =0.9-\left(0.9-q_{M S}\right) \exp \left(-\lambda_{M S} T\right) \\
\widetilde{q}_{L S} & =\widetilde{q}_{M S}-\left(\widetilde{q}_{M S}-q_{L S}\right) \exp \left(-\lambda_{L S} T\right)
\end{aligned}
$$

if skills are inherently asymmetric. ${ }^{20}$ Otherwise, we can use the committee mean competence: ${ }^{21}$

$$
\widetilde{q}=0.9-(0.9-q) \exp (-\lambda T)
$$

Moreover, note that the above conditional probabilities do not depend on the actual sequence but on the number of votes. Replacing the individual skills with the average and summarizing all possible sequences of $x$ out of $n$ votes casted for the same alternative by binomial coefficients $\left(\begin{array}{l}n \\ x\end{array}\right)$ we can subsequently use expected conditional probabilities to assess the quality of the committee decision-making. To this we now turn.

\section{Quality of interest rate decisions}

In the set-up described above, the quality of the collective decision of the MPC, which ex hypothesi is taken by simple majority ${ }^{22}$, is a function of the

\footnotetext{
${ }^{18}$ In this case $P_{2}(B \mid b)=0$ and $P_{3}(B \mid b)=\sum_{\substack{S_{b} \subset M \\ s_{b} \geq k_{b}}} \prod_{i \in S_{b}} \widetilde{q}_{i} \prod_{i \notin S_{b}}\left(1-\widetilde{q}_{i}\right)$.

${ }^{19}$ Note that if board members do not vote interdependently, then $k_{b}$ in the above expressions becomes equal to $m$. As a result (9) becomes equivalent to (5).

${ }^{20} q_{M S}$ denotes the average inherent expertise of the more-skilled committee members, whereas $q_{L S}$ denotes the average for the less-skilled committee members. The learning rates are given as: $\lambda_{M S}=1$ and $\lambda_{L S}=\omega$.

${ }^{21} q$ is the mean inherent competence of all committee members. The common learning rate is $\lambda=1$.

${ }^{22}$ Although realistic, this rule is formally optimal under very restrictive conditions only. See Berk and Bierut (2003) for a discussion of the effects of different voting rules.
} 
competence of the members. This is related to interaction or learning. If the MPC meeting is preceded by an informal prior board meeting, and when members in both meetings interact, the final expertise of MPC members becomes heterogenous, even if it has been homogeneous initially. Figure 1 below illustrates this, for initially symmetric skills set at $q=0.6$, a board of size 6 and a MPC of 19 members. The policy meeting lasts from time $T=0$ until $T=1$. The dashed line to the left represents the skills of board members, and the dashed line to the right the skills of non-board members (learning rates $\lambda_{B}=1$ and $\lambda_{N B}=\frac{m}{n}=\frac{6}{19}$ ). The single solid line represents (for completeness) the case of a single MPC meeting only (no prior board meeting) with all members interacting simultaneously (which implies a learning rate $\lambda_{B}=\lambda_{N B}=1$ ).

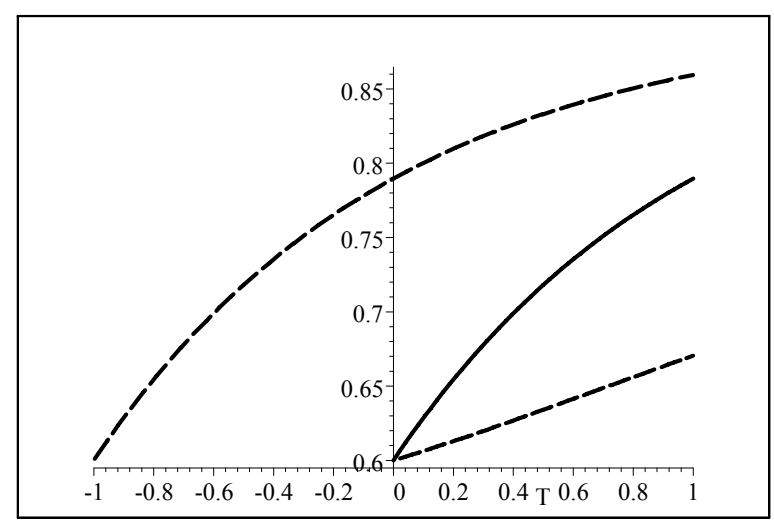

Figure 1. The learning processes

The graph clearly shows that learning in both the prior board meeting and the policy meeting makes the board better off than would be the case when learning occurred only in the MPC meeting. The reverse holds for non-board members. This is due to the catching-up effect of learning. When there is only a single policy meeting, non-board committee members improve their skills 'catching up' to the maximum level of $90 \%$ accuracy, whereas in the other case their skills 'catch up' to the board members' expertise, which is below the maximum. Which process leads to a higher collective expertise depends on the composition of the committee, i.e. the shares of board and non-board members. In any case, interaction improves the expertise of committee members. Proposition 1 follows directly.

Proposition 1 Interaction among committee members improves the quality of the collective decision-making process.

Proof. See Appendix A.1. 
The proof holds, regardless of an initial skill differential between board and other committee members. We illustrate the no-differential situation in Figures 2 and 3 below. The graphs depict the effects of interaction on the probability that the MPC takes the correct decision (denoted as EP), for two committee sizes: 19 and 9 . In the first committee, the board of 6 members is in minority, in the second - in majority. The former case may therefore be interpreted as relevant for the ECB Governing Council and the latter as relevant for the FOMC. Dotted lines denote the no-interaction (and therefore no-learning) case (i.e. simple voting on interest rates). Dashed lines refer to the case in which learning is limited to board members. Solid lines refer to learning involving all committee members, both simultaneously (i.e. when there only is a MPC meeting: thin lines) and in two stages (informal prior board meeting and MPC meeting: medium lines). The lines are drawn as a function of inherent (homogeneous) average decisional skills $q$, under the assumption that the time allotted for taking a decision equals 1 period.

In both committees, the highest quality of the collective decision is attained when all committee members are involved in interaction and learning. In a small committee, a single policy meeting yields inferior results relative to an informal board meeting preceding the policy meeting, since in the latter case the majority of committee members (i.e. the board) interacts twice and hence has twice as much time to improve their skills. In the large committee, the quality of the collective decision is best served by allowing only for a single policy meeting, in which all members learn and improve their skills. Simply convening and mechanistically voting on interest rates yields by far the worst results, regardless of committee size.

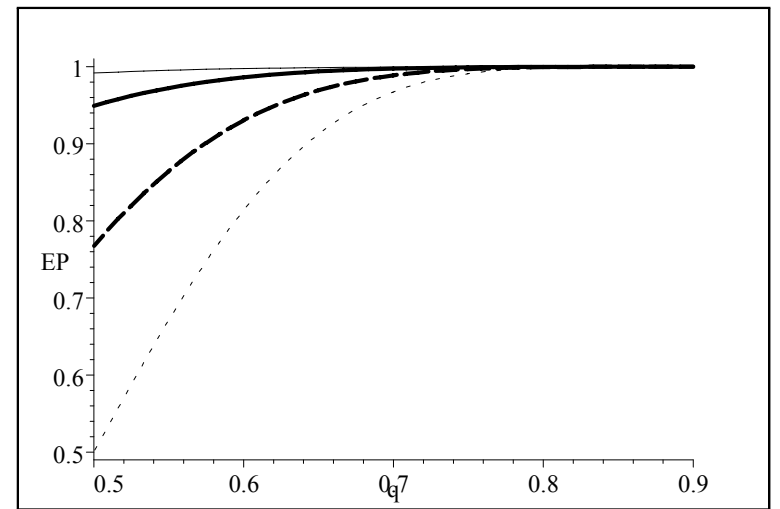

Figure 2. Effects of learning on the accuracy of the MPC decision (a large MPC) 


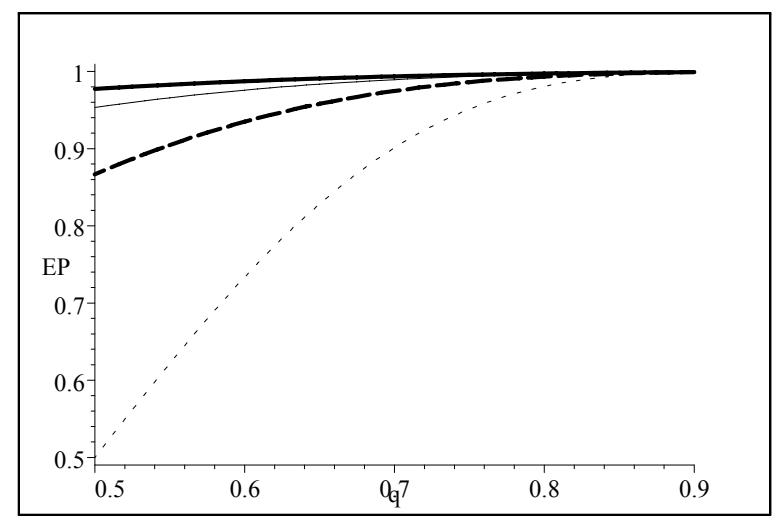

Figure 3. Effects of learning on the accuracy of the MPC decision (a small MPC)

The conclusions stated above are in contrast to the conclusions made earlier in the literature (see, for example, Nitzan and Paroush, 1985, Ladha, 1992, and Ladha, 1995), where interaction is generally found to be detrimental to the accuracy of collective decision-making. This contrast stems from a different interpretation of interaction. The above-mentioned authors assume that interaction coincides with interdependent voting, whereas we assume that interaction coincides with learning and may result in interdependent voting. We prefer our interpretation, as we think it is important to allow for the possibility that partners in a discussion (interaction) fail to convince each other. Indeed, Proposition 2 shows that interdependent voting is not identical to interaction among committee members, if they are interested in maximizing the accuracy of the collective decision.

Proposition 2 In interactive committees interdependent voting behavior is unlikely, provided that the members' primary interest is in the accuracy of the collective decision.

Proof. See Appendix A.2.

It follows from Appendix 2 that there exist only a limited number of situations in which interdependent voting may be the optimal strategy; they require that board members on average possess a significantly higher skill level and have a learning monopoly (i.e. only the board members are able to learn). Alternatively, this situation will arise when the committee size becomes extremely large so that non-board members cannot increase their skills with learning, whereas the board in its informal prior meeting is able to learn. Neither condition is likely to be satisfied in real-life. Interest rate decisions are not taken without discussions among all MPC members and MPC's are not extremely large. Furthermore, MPC members are selected according to their expertise, suggesting relatively high and similar expertise. 
Again we illustrate our conclusions graphically. Figures 4, 5 (both graphs assume a relatively small MPC not dominated by the board, i.e. $n=19$ ) and 6 (which replicates figure 5 for a very large committee, i.e. $n=39$ ) present the effects of interdependent voting behavior on the accuracy of the collective decision taken by a committee composed of equally skilled members. ${ }^{23}$ Starting from a set-up in which an informal board meeting precedes the actual policy meeting, learning can occur in the informal meeting only (figure 4) or in both meetings (figure 5). Dotted lines depict the evolution of the probability of taking the correct collective decision assuming all members base their vote on their own opinion. Dashed lines assume a coalition of the board (i.e. a common position), and solid lines assume that other MPC members follow the board (the latter line obviously is not drawn in figure 4).

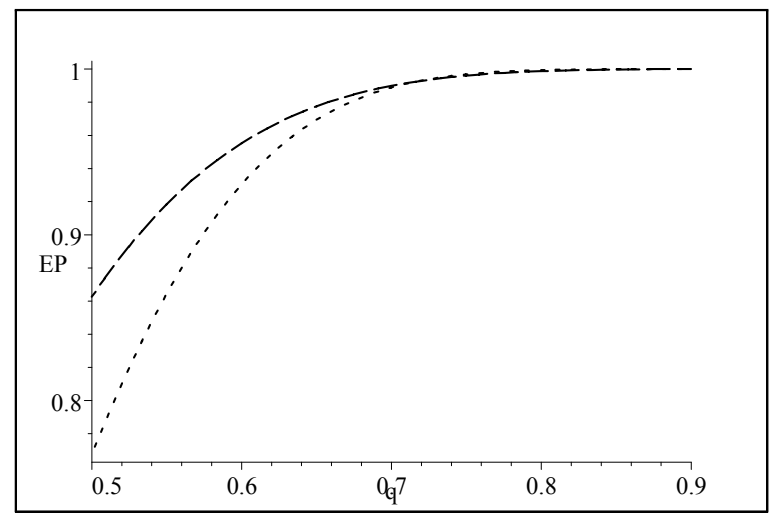

Figure 4. Effects of interdependent voting on the accuracy of the MPC decision (interaction occurs once)

\footnotetext{
${ }^{23}$ I.e. we assume $q_{B}=q_{N B}=q$. The results under heterogeneous skills are presented below (figures 7 and 8). All figures assume a board of size 6, and that a majority of 4 suffices for a common position in the board (this implies the highest likelihood of consensual behaviour). Moreover, we assume that the time alloted for discussions equals 1 period, both for the informal meeting (if it occurs) and for the policy meeting.
} 


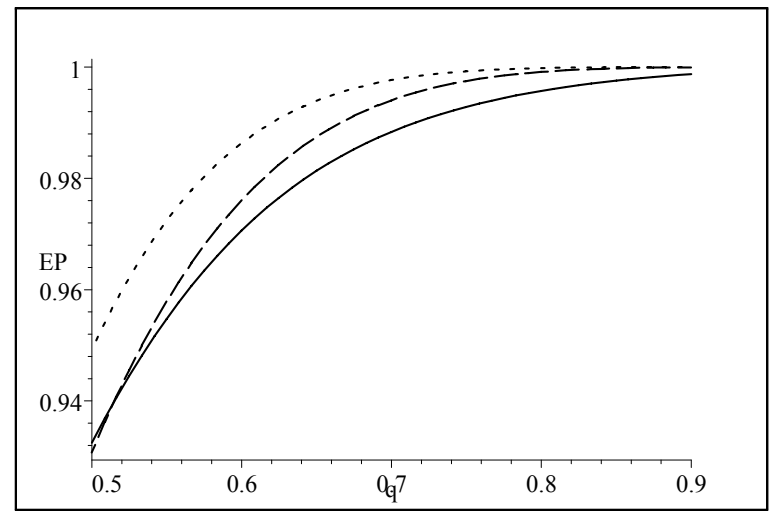

Figure 5. Effects of interdependent voting on the accuracy of the MPC decision (interaction occurs twice)

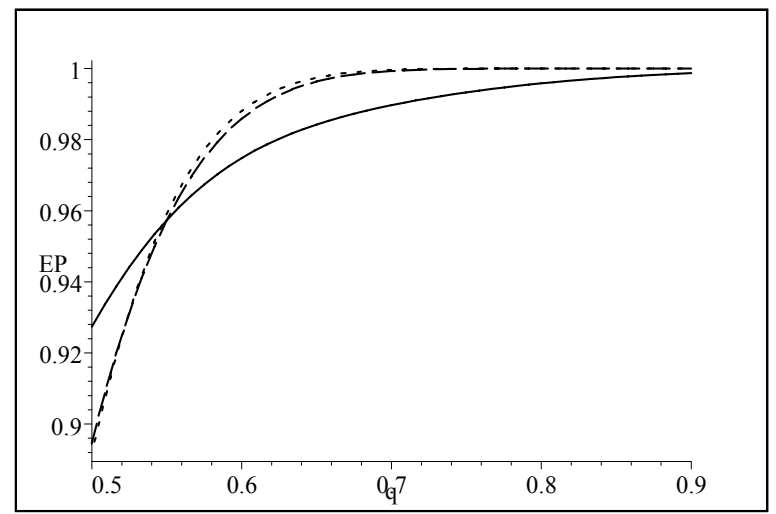

Figure 6. Effects of interdependent voting on the accuracy of the MPC decision (interaction occurs twice, a very large MPC)

Without interaction in the policy meeting, the prior informal meeting of board members is the only forum for increasing valuable expertise. ${ }^{24}$ In such a case taking a common position on interest rates by the board is beneficial for the quality of the collective outcome since it reinforces the position of members who have effectively higher expertise and who are therefore more likely to be correct. The reasoning is similar if interaction takes place both in the informal meeting and in the policy meeting, but when the committee size is so large that learning has a negligible effect on the skills of non-board committee members.

If all committee members can interact and effectively learn, independent voting delivers the most accurate collective decisions, and therefore should be the dominant strategy of committee members. This result is intuitive: improved expertise is too valuable to be wasted.

\footnotetext{
${ }^{24}$ This requires of course that time is not scarce.
} 
These results above carry through to the case of asymmetric inherent skills, as figures 7 and 8 below illustrate (drawn for $n=19$, additional assumptions are: $q_{B}=0.8$ and $q_{N B} \leq 0.8$ (measured on the X-axis)). Note that with symmetric skills it took a large committee size to make interdependent voting an optimal strategy (figure 6), whereas a bias in initial skills reduces the committee size above which interdependent voting dominates independent voting (in the case when the policy meeting involves interaction).

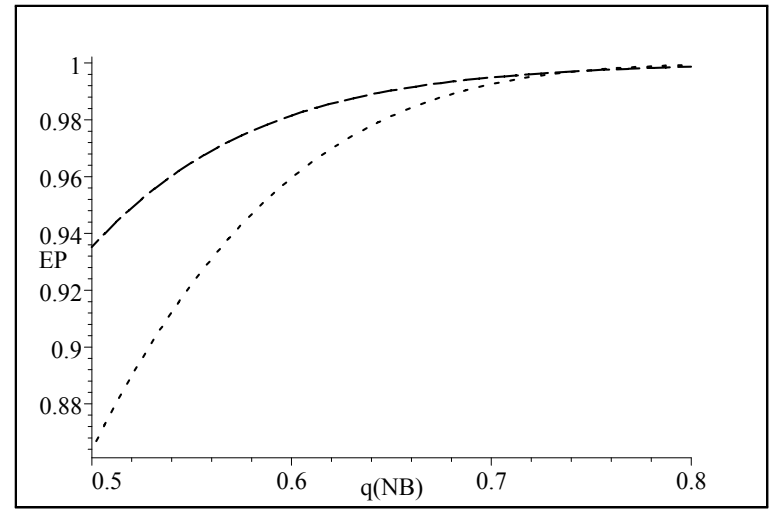

Figure 7. Effects of interdependent voting on the accuracy of the MPC decision (interaction occurs once)

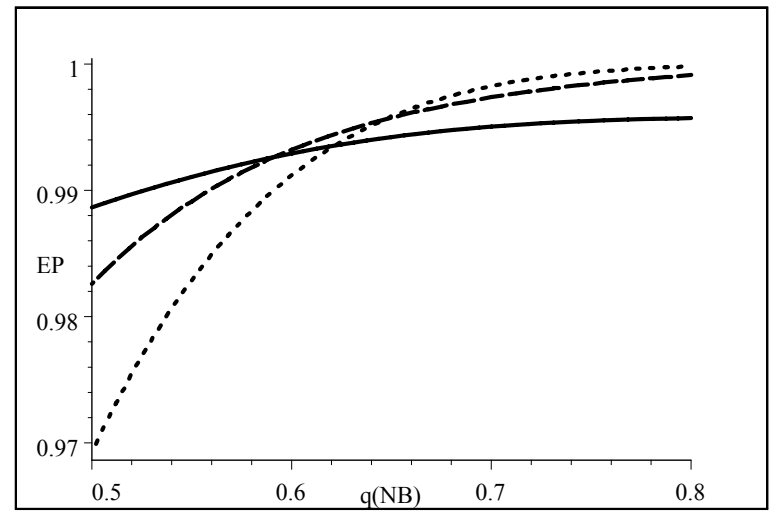

Figure 8. Effects of interdependent voting on the accuracy of the MPC decision (interaction occurs twice)

These results lead to some interesting policy interpretations. First, if one prefers a monetary policy committee in which members learn from each other and subsequently use the acquired expertise to vote on interest rates, one should (i) prevent a systematic differential in skills between the 'hub' and the 'spokes', (ii) allow for interaction in the policy meeting (i.e. among all MPC members), and (iii) keep the committee size limited. In such a situation, committee members interested in their reputation will not have incentives to forego their private opinion and follow the majority view. 


\section{Optimal committee size}

The upshot from the preceding analysis is that interaction is beneficial for group decision-making. However, discussions take time, and extending the time allotted to the committee to take a decision is costly. The improvement in the collective outcome thus does not come without a cost. Neither should we expect that individuals participate in decision-making bodies for purely altruistic motives. Their participation usually involves paying salaries. Therefore the total cost is related to the size of the committee as well as the time it requires to take a decision. Since the quality of the collective decision also depends on both variables, we can calculate the optimal size and learning time of a committee, given its structure, average inherent skills (assumed to be homogeneous) and costs involved.

We capture both types of costs by the following function:

$$
C(n, T)=\alpha n+\exp (\beta T)-1
$$

where $\alpha, \beta>0$. The former parameter denotes the constant cost per committee member (see also Gradstein, Nitzan and Paroush, 1990). Time costs are assumed to be non-linear, which can be motivated by real-life relevance. The meetings of the FOMC or the ECB Governing Council have a more or less pre-announced duration. Then, if a meeting exceeds the pre-announced deadline, economic agents may interpret this as a sign that the decision to be taken is a contentious one - possibly an indication of a disagreement among the decision-makers. In other words, financial markets may negatively interpret a longer-then-expected duration of the meeting, and may even question the quality of the decision taken (thus the credibility of the central bank is negatively affected). If one assumes that this type of effects is likely to accumulate the longer the meeting lingers on, then the time-related costs should be modelled in a nonlinear fashion.

We measure the quality of committee decision-making process by the conditional expected probability that the committee takes the correct decision:

$$
\Pi(n, T)=E P(B \mid b)
$$

Based on the previous sections, we characterize the benefit function as follows:

$$
\begin{aligned}
\frac{\partial \Pi(n, T)}{\partial n} & =\frac{\partial E P(B \mid b)}{\partial n}+\frac{\partial E P(B \mid b)}{\partial \widetilde{q}} \frac{\partial \widetilde{q}}{\partial \lambda} \frac{\partial \lambda}{\partial n} \\
& =\frac{\partial E P(B \mid b)}{\partial n}+\frac{\partial \lambda}{\partial n} T(\bar{q}-q) \exp (-\lambda T) \frac{\partial E P(B \mid b)}{\partial \widetilde{q}} \geq 0 \\
\frac{\partial \Pi(n, T)}{\partial T} & =\frac{\partial E P(B \mid b)}{\partial \widetilde{q}} \frac{\partial \widetilde{q}}{\partial T}=\lambda(\bar{q}-q) \exp (-\lambda T) \frac{\partial E P(B \mid b)}{\partial \widetilde{q}} \geq 0
\end{aligned}
$$


These equations show, on the one hand, that increasing the number of committee members has a non-negative effect on the collective outcome, which corresponds to the Condorcet Jury Theorem (Condorcet, 1785). On the other hand, as can be seen from equation (2) in section 2, admitting more members reduces the positive effects of granting the committee more time to discuss and decide, because the increased committee size reduces the effectiveness of learning.

The optimal committee size and the learning time then follow from the first order conditions:

$$
\begin{aligned}
& \frac{\partial \Pi\left(n^{*}, T\right)}{\partial n}=\frac{\partial C\left(n^{*}, T\right)}{\partial n}=\alpha \\
& \frac{\partial \Pi\left(n, T^{*}\right)}{\partial T}=\frac{\partial C\left(n, T^{*}\right)}{\partial T}=\beta \exp (\beta T)
\end{aligned}
$$

The tables below present the optimal combinations of committee size $n^{*}$ and learning time $T^{*}$ together with the resulting net benefit $\Pi\left(n^{*}, T^{*}\right)-C\left(n^{*}, T^{*}\right)$. The first table presents the results for the set-up in which there only is a single meeting (i.e. the policy meeting), and a set-up which entails both a prior informal board meeting and a MPC meeting. Learning in the latter case is limited to the board meeting. ${ }^{25}$ The second table presents the results for the situation of both an informal board meeting and a MPC meeting, with learning both in the board and in the policy meeting. ${ }^{26}$ The results are calculated under the assumption that decisional competence of committee members is equal on average (by way of illustration set at 0.6). Furthermore, we retain the earlier assumptions regarding the size of the board $(m=6)^{27}$ and the threshold for the board to take a common position $\left(k_{b}=4\right)$. In the case when an informal board meeting takes place, members can either follow the majority position of the board, if it exists, $(I N T)$ or vote individually

\footnotetext{
${ }^{25}$ In both cases the learning rate of interacting members equals unity (for all committee members or just for board members, respectively).

${ }^{26}$ In this case the learning rate is heterogeneous among committee members: $\lambda_{B}=1$ and $\lambda_{N B}=\frac{m}{n}<1$.

${ }^{27}$ This assumption implies that $n^{*} \geq 7$.
} 
$(I N D)$.

\begin{tabular}{||c||c||c|c||c|c||c|c|}
\hline \hline \multicolumn{1}{||c||}{} & \multicolumn{2}{c||}{ MPC only } & \multicolumn{3}{c|}{ Board+MPC, learning only in Board } \\
\hline \hline \multicolumn{2}{||c||}{$\left(\delta_{B}, \delta_{N B}\right)^{28}$} & \multicolumn{2}{c||}{$(I N D, I N D)$} & \multicolumn{2}{c|}{$(I N D, I N D)$} & \multicolumn{2}{c|}{$(I N T, I N D)$} \\
\hline \hline$\alpha$ & $\beta$ & $\left(n^{*}, T^{*}\right)$ & $\Pi-C$ & $\left(n^{*}, T^{*}\right)$ & $\Pi-C$ & $\left(n^{*}, T^{*}\right)$ & $\Pi-C$ \\
\hline \multirow{2}{*}{0.001} & 0.05 & $(27,0.50)$ & 0.94 & $(7,1.23)$ & 0.89 & $(7,1.61)$ & 0.85 \\
& 0.25 & $(57,0.09)$ & 0.89 & $(75,0)$ & 0.89 & $(7,0.57)$ & 0.64 \\
\hline \multirow{2}{*}{0.002} & 0.05 & $(17,0.67)$ & 0.92 & $(7,1.23)$ & 0.88 & $(7,1.61)$ & 0.85 \\
& 0.25 & $(35,0.17)$ & 0.85 & $(51,0)$ & 0.82 & $(7,0.57)$ & 0.63 \\
\hline \multirow{2}{*}{0.003} & 0.05 & $(13,0.79)$ & 0.90 & $(7,1.23)$ & 0.87 & $(7,1.61)$ & 0.84 \\
& 0.25 & $(27,0.21)$ & 0.82 & $(37,0)$ & 0.78 & $(7,0.57)$ & 0.62 \\
\hline \multirow{2}{*}{0.004} & 0.05 & $(11,0.88)$ & 0.89 & $(7,1.23)$ & 0.87 & $(7,1.61)$ & 0.83 \\
& 0.25 & $(21,0.25)$ & 0.80 & $(29,0)$ & 0.75 & $(7,0.57)$ & 0.62 \\
\hline \multirow{2}{*}{0.005} & 0.05 & $(9,0.95)$ & 0.88 & $(7,1.23)$ & 0.86 & $(7,1.61)$ & 0.83 \\
& 0.25 & $(19,0.27)$ & 0.78 & $(23,0)$ & 0.72 & $(7,0.57)$ & 0.61 \\
\hline
\end{tabular}

\begin{tabular}{||c||c||c|c||c|c||c|c|}
\hline \hline \multicolumn{1}{||c||}{} & \multicolumn{5}{c||}{ Board+MPC, learning in Board+ in MPC } \\
\hline \hline$\left(\delta_{B}, \delta_{N B}\right)$ & $(I N D, I N D)$ & \multicolumn{2}{c|}{$(I N T, I N D)$} & \multicolumn{2}{c|}{$(I N T, I N T)$} \\
\hline \hline$\alpha$ & $\beta$ & $\left(n^{*}, T^{*}\right)$ & $\Pi-C$ & $\left(n^{*}, T^{*}\right)$ & $\Pi-C$ & $\left(n^{*}, T^{*}\right)$ & $\Pi-C$ \\
\hline \multirow{2}{*}{0.001} & 0.05 & $(7,0.81)$ & 0.93 & $(7,1.61)$ & 0.85 & $(7,1.61)$ & 0.85 \\
& 0.25 & $(75,0)$ & 0.89 & $(7,0.57)$ & 0.64 & $(7,0.57)$ & 0.64 \\
\hline \multirow{2}{*}{0.002} & 0.05 & $(7,0.81)$ & 0.92 & $(7,1.61)$ & 0.85 & $(7,1.61)$ & 0.85 \\
& 0.25 & $(7,0.37)$ & 0.81 & $(7,0.57)$ & 0.63 & $(7,0.57)$ & 0.63 \\
\hline \multirow{2}{*}{0.003} & 0.05 & $(7,0.81)$ & 0.92 & $(7,1.61)$ & 0.84 & $(7,1.61)$ & 0.84 \\
& 0.25 & $(7,0.37)$ & 0.80 & $(7,0.57)$ & 0.62 & $(7,0.57)$ & 0.62 \\
\hline \multirow{2}{*}{0.004} & 0.05 & $(7,0.81)$ & 0.91 & $(7,1.61)$ & 0.83 & $(7,1.61)$ & 0.83 \\
& 0.25 & $(7,0.37)$ & 0.80 & $(7,0.57)$ & 0.62 & $(7,0.57)$ & 0.62 \\
\hline \multirow{2}{*}{0.005} & 0.05 & $(7,0.81)$ & 0.90 & $(7,1.61)$ & 0.83 & $(7,1.61)$ & 0.83 \\
& 0.25 & $(7,0.37)$ & 0.79 & $(7,0.57)$ & 0.61 & $(7,0.57)$ & 0.61 \\
\hline
\end{tabular}

A prior informal meeting of board members creates an informational advantage for them: they exchange their views and improve their competence. This advantage is fully exploited in the optimum, and as a result almost inevitably the committee size is reduced to a minimum of 7 members (a boarddominated committee), unless learning is expensive. Moreover, the highest net benefit (the highest collective outcome) is reached assuming members base their vote on their own views, ie independent voting.

The informational advantage obviously disappears if there is no informal meeting. In this case, the optimal solution for the committee size is interior,

\footnotetext{
${ }^{28} \delta_{B}$ and $\delta_{N B}$ denote the strategy choices of board and non-board members, respectively (i.e. to vote independently or to take over the view of other members).
} 
and much larger. Furthermore, compared to the best possible collective outcome to be reached in a set-up including a prior informal meeting (attained under independent voting), the net benefit is only marginally larger, ${ }^{29}$ and the optimal amount of time necessary for carrying out discussions is smaller. The latter results are due to the fact that with a prior informal meeting the total time spent on interaction by the board in a committee dominated by the board is much larger: not only is $T^{*}$ larger, but the board effectively spends $2 T^{*}$ interacting.

Even though interaction results in a large reduction in the optimal committee size, we still observe a trade-off between the optimal number of committee members and the optimal amount of learning time. For example we observe the following cases of a trade-off: in a single policy meeting the same net benefit of 0.89 is obtained for the solutions: $(57,0.09)$ and $(11,0.88)$, if the board meets prior to the MPC then the solutions $(7,1.23)$ and $(75,0)$ yield 0.89 in the case when the MPC meeting does not involve interaction, and $(75,0)$ and $(7,0.81)$ yield $0.89 / 0.90$ in the case when the policy meeting does involve interaction. As a result a committee designer faces a certain degree of flexibility between the number of committee members and the amount of time they should be allotted to reach the most accurate decision.

\section{Conclusions}

Our results have interesting implications for actual monetary policy making, when conducted in a committee. First of all, we show that what policy makers in real life indicate to be an important characteristic of monetary policy committees, interaction, is beneficial for the quality of interest rate decisions, since committee members learn from each other. Secondly, interactive committees do not necessarily imply that members forego their own opinion and follow the majority. In other words: members discuss the decision but do not necessarily convince each other of their views. We show that interaction (i.e. improving one's expertise) without interdependent voting (i.e. wasting one's expertise) is the best decision-making procedure, except under certain restrictive conditions.

Another implication regards the committee design: our results suggest that there exists a certain degree of flexibility between the decision time and the number of decision-makers: (1) if decisions are to be reached very quickly (learning time is costly), the committee should be large; (2) if there is sufficient time to take the collective decision (time is relatively cheap), the committee size can be reduced, provided that two conditions are fulfilled:

\footnotetext{
${ }^{29}$ Unless the cost per member becomes very high.
} 
all committee members are involved in an exchange of views and learn from each other, and all committee members vote following their own judgement. Under such circumstances both procedures will yield similar net benefits.

We would like to conclude by stating that, while the main motivation of this research is based on real life, i.e. the 'hub-and-spokes' monetary policy committees of the US Federal Reserve and the ECB, our analysis is highly stylized and contains some important caveats. This should be kept in mind when interpreting our results. An example of such a caveat is that in our simple setup the only value added the board can provide is in terms of improving the quality of decision-making in the committee. This is clearly a simplification of reality, where 'hub-and-spokes' committees tend to be motivated by other arguments, see Meade and Sheets (forthcoming). Other important caveats include the single-shot nature of our analysis, which clearly is at odds with the fact that monetary policy decisions are taken on a regular basis, so that the intertemporal dimension may be relevant for the current setting of interest rates. We plan to take up the latter issue in future research.

\section{References}

1. Arrow K.J. "Social Choice and Individual Values", 2nd edition, Yale University Press, 1963

2. De Nederlandsche Bank "The role of national central bank in the single European monetary policy", Quarterly Bulletin, March 2000

3. Austen-Smith D. and J.S. Banks "Information Aggregation, Rationality, and the Condorcet Jury Theorem", American Political Science Review, 90(1), March 1996

4. Belden S. "Policy Preferences of FOMC Members as Revealed by Dissenting Votes", Journal of Money, Credit, and Banking, 21(4), November 1989

5. Ben-Yashar R.C. and S.I. Nitzan "The optimal decision rule for fixedsize committees in dichotomous choice situations: the general result", International Economic Review, 38(1), February 1997

6. Berk J.M. and B.K. Bierut "Committee Structure and its Implications for Monetary Policy Decision-Making", Tinbergen Institute Discussion Paper 2003-053/2, 2003

7. Blinder A.S. "Central banking in theory and practise", MIT Press, 1998 
8. Blinder A.S. and J. Morgan "Are Two Heads Better Than One?: An Experimental Analysis of Group", NBER Working Paper 7909, 2000

9. Condorcet N.C. de "Essai sur l'application de l'analyse à la probabilité des decisions rendues a la pluralité des voix", Paris, L'imprimerie royale, 1785

10. Evans G.W. and S. Honkapohja "Learning and Expectations in Macroeconomics", Princeton University Press, 2001

11. Gildea J.A. "The Regional Representation of Federal Reserve Banks Presidents", Journal of Money, Credit, and Banking, 24(2), May 1992

12. Goldstein L.J., D.C. Lay and D.I. Schneider "Calculus and its applications", Prentice-Hall International, 1993

13. Goodfriend M. "The role of a regional bank in a system of central banks", Federal Reserve Bank of Richmond Working Paper No. 99-4, July 1999

14. Gradstein M., Nitzan S. and J. Paroush "Collective decision making and the limits on the organization's size", Public Choice, 66(3), September 1990

15. Grofman B., G. Owen and S.L. Feld "Average Competence, Variability in Individual Competence, and Accuracy of Statistically Pooled Group Decisions", Psychological Reports, 50, 1982

16. Grofman B., G. Owen and S.L. Feld "Thirteen Theorems in Search of the Truth", Theory and Decision, 15, 1983

17. Hefeker, C. "Federal Monetary Policy", Scandinavian Journal of Economics, 105 (4), pp. 643-659, December 2003

18. Ladha K.K.: "Condorcet's Jury Theorem in Light of de Finetti's Theorem: Majority-Rule Voting with Correlated Votes", Social Choice and Welfare, 10(1), January 1993

19. Ladha K.K. "Information pooling through majority-rule voting: Condorcet's jury theorem with correlated votes", Journal of Economic Behavior and Organization, 26(3), May 1995

20. Ladha K.K. "The Condorcet Jury Theorem, Free Speech, and Correlated Votes", American Journal of Political Science, 36(3), August 1992 
21. Lombardelli C., J. Proudman and J. Talbot "Committees versus individuals: an experimental analysis of monetary policy decision-making", Bank of England Working Paper no. 165, 2002

22. Meade E.E. and D.N. Sheets "Regional Influences on U.S. Monetary Policy", Journal of Money, Credit, and Banking, forthcoming

23. Nitzan S. and J. Paroush "Collective Decision Making. An Economic Outlook", Cambridge University Press, 1985

24. Owen G., B. Grofman and S.L. Feld "Proving a Distribution-Free Generalization of the Condorcet Jury Theorem", Mathematical Social Sciences, 17(1), February 1989

25. Sen A.K. "Collective Choice and Social Welfare", Holden-Day Inc., 1970

26. Sen A.K. "Social Choice Theory: A Re-examination.", Econometrica, 45, January 1977

27. Sibert A. "Monetary Policy Committees: Individual and Collective Reputations", Review of Economic Studies, 70(3), July 2003

28. Swank O. and P. Wrasai "Deliberation, Information Aggregation and Collective Decision Making", Tinbergen Institute Discussion Paper 2002006/1, 2002

29. von Hagen J. and R. Süppel "Central Bank Constitutions for Federal Monetary Unions", European Economic Review, 38(3-4), April 1994

\section{Appendix}

\subsection{Appendix A.1. Proof to Proposition 1}

Proposition 1: Interaction among committee members improves the quality of the collective decision-making process.

Proof: The quality of the collective decision-making process is given by 
the conditional probability $E P(B \mid b)$ :

$$
\begin{aligned}
E P(B \mid b)= & \left.\sum_{s_{b}=0}^{m}\left(\begin{array}{c}
m \\
s_{b}
\end{array}\right) \widetilde{q}_{B}^{s_{b}}\left(1-\widetilde{q}_{B}\right)^{m-s_{b}} \sum_{s=\frac{n+1}{2}-s_{b}}^{n-m}\left(\begin{array}{c}
n-m \\
s
\end{array}\right) \widetilde{q}_{N B}^{s}\left(1-\widetilde{q}_{N B}\right)^{n-m-s}\right) \\
= & \left(1-\widetilde{q}_{B}\right)^{m} \sum_{s=\frac{n+1}{2}}^{n-m}\left(\begin{array}{c}
n-m \\
s
\end{array}\right) \widetilde{q}_{N B}^{s}\left(1-\widetilde{q}_{N B}\right)^{n-m-s} \\
& +m\left(1-\widetilde{q}_{B}\right)^{m-1} \widetilde{q}_{B} \sum_{s=\frac{n+1}{2}-1}^{n-m}\left(\begin{array}{c}
n-m \\
s
\end{array}\right) \widetilde{q}_{N B}^{s}\left(1-\widetilde{q}_{N B}\right)^{n-m-s} \\
& +\ldots \\
& +m \widetilde{q}_{B}^{m-1}\left(1-\widetilde{q}_{B}\right) \sum_{s=\frac{n+1}{2}-(m-1)}^{n-m}\left(\begin{array}{c}
n-m \\
s
\end{array}\right) \widetilde{q}_{N B}^{s}\left(1-\widetilde{q}_{N B}\right)^{n-m-s} \\
& +\widetilde{q}_{B}^{m} \sum_{s=\frac{n+1}{2}-m}^{n-m}\left(\begin{array}{c}
n-m \\
s
\end{array}\right) \widetilde{q}_{N B}^{s}\left(1-\widetilde{q}_{N B}\right)^{n-m-s}
\end{aligned}
$$

where $\widetilde{q}_{B}$ denotes the learned skills of board members, and $\widetilde{q}_{N B}$ the learned skills of non-board committee members. Since

$$
\begin{aligned}
\frac{\partial}{\partial q}\left(q^{x}(1-q)^{m-x}\right) & =\frac{x-q m}{q(1-q)} q^{x}(1-q)^{m-x} \\
x & \geq q m \Leftrightarrow \frac{\partial}{\partial q}\left(q^{x}(1-q)^{m-x}\right) \geq 0 \\
x & <q m \Leftrightarrow \frac{\partial}{\partial q}\left(q^{x}(1-q)^{m-x}\right)<0
\end{aligned}
$$

then an increase in $\widetilde{q}_{B}$ lowers (increases) $\widetilde{q}_{B}^{s_{b}}\left(1-\widetilde{q}_{B}\right)^{m-s_{b}}$ for low (high) values of $s_{b}$. The total effect is positive, since: (1) $\widetilde{q}_{B} \geq 0.5$ and therefore $\widetilde{q}_{B}^{x} \geq$ $\left(1-\widetilde{q}_{B}\right)^{x}$ for all $x \geq 0$, and $(2)$ the series $\sum_{s=\frac{n+1}{2}-x}^{n-m}\left(\begin{array}{c}n-m \\ s\end{array}\right) \widetilde{q}_{N B}^{s}\left(1-\widetilde{q}_{N B}\right)^{n-m-s}$ is longer (by $x$ elements) than the series $\sum_{s=\frac{n+1}{2}}^{n-m}\left(\begin{array}{c}n-m \\ s\end{array}\right) \widetilde{q}_{N B}^{s}\left(1-\widetilde{q}_{N B}\right)^{n-m-s}$ and therefore the sum of the first is larger than the sum of the latter (all elements in the series are positive). As a result

$$
\frac{\partial E P(B \mid b)}{\partial \widetilde{q}_{B}}>0
$$

The reasoning is analogous for the skills of the non-board members, since $E P(B \mid b)$ can be re-written as:

$$
E P(B \mid b)=\sum_{s=0}^{n-m}\left(\left(\begin{array}{c}
n-m \\
s
\end{array}\right) \widetilde{q}_{N B}^{s}\left(1-\widetilde{q}_{N B}\right)^{n-m-s} \sum_{s_{b}=\frac{n+1}{2}-s}^{m}\left(\begin{array}{c}
m \\
s_{b}
\end{array}\right) \widetilde{q}_{B}^{s_{b}}\left(1-\widetilde{q}_{B}\right)^{m-s_{b}}\right)
$$


As a result

$$
\frac{\partial E P(B \mid b)}{\partial \widetilde{q}_{N B}}>0
$$

We define interaction as a process, which involves time and learning. Therefore its effect on the skills of committee members is given as:

$$
\frac{\partial \widetilde{q}_{i}}{\partial T}=\lambda_{i}\left(\bar{q}_{i}-\widetilde{q}_{i}\right)\left\{\begin{array}{l}
=0 \text { if } \widetilde{q}_{i}=\bar{q}_{i} \\
>0 \text { if } \widetilde{q}_{i}<\bar{q}_{i}
\end{array}\right\}
$$

As a result interaction is always beneficial for the quality of the collective decision. In the decision-making process involving only the MPC including interaction, all members interact simultaneously and hence they all improve their skills. In the set-up with both a prior informal board meeting and a MPC meeting, the interaction and learning takes place once or twice. In either case, however, the skills of interacting members increase. Higher skills imply higher $E P(B \mid b)$. Q.E.D.

\subsection{Appendix A.2. Proof to Proposition 2}

Proposition 2: In interactive committees interdependent voting behavior is unlikely, provided that the members' primary interest is in the accuracy of the collective decision.

Proof: Obviously, interdependent voting can only occur in the set-up with both a prior informal board meeting and a MPC meeting, as described in section 3. In this case committee members have the choice to follow the majority position of the board, if it exists, $(I N T)$ or vote individually $(I N D)$; the strategy space is therefore given by $\delta=\{I N T, I N D\}$. The incentives of committee members are by assumption related to the quality of the collective decision-making process:

$$
U_{i: i \in N}(\delta)=\Pi_{i}(\delta)=E P_{\delta}(B \mid b)
$$

Therefore the choice of strategy depends on the delivered decision quality.

Case 1. Learning in the informal board meeting only

In this case only board members face the choice between the two strategies; other committee members do not have the opportunity to learn about the existence or lack of the common position in the board and hence they vote individually.

Individual voting of board members delivers the following utility:

$$
\Pi_{B}(I N D)=\sum_{s_{b}=0}^{m}\left(\left(\begin{array}{c}
m \\
s_{b}
\end{array}\right) \widetilde{q}_{B}^{s_{b}}\left(1-\widetilde{q}_{B}\right)^{m-s_{b}} \sum_{s=\frac{n+1}{2}-s_{b}}^{n-m}\left(\begin{array}{c}
n-m \\
s
\end{array}\right) q_{N B}^{s}\left(1-q_{N B}\right)^{n-m-s}\right)
$$


whereas voting interdependently:

$$
\begin{aligned}
\Pi_{B}(I N T)= & \sum_{s_{b}=m-k_{b}+1}^{k_{b}-1}\left(\left(\begin{array}{l}
m \\
s_{b}
\end{array}\right) \widetilde{q}_{B}^{s_{b}}\left(1-\widetilde{q}_{B}\right)^{m-s_{b}} \sum_{s=\frac{n+1}{2}-s_{b}}^{n-m}\left(\begin{array}{c}
n-m \\
s
\end{array}\right) q_{N B}^{s}\left(1-q_{N B}\right)^{n-m-s}\right) \\
& +\sum_{s_{b}=k_{b}}^{m}\left(\begin{array}{c}
m \\
s_{b}
\end{array}\right) \widetilde{q}_{B}^{m-s_{b}}\left(1-\widetilde{q}_{B}\right)^{s_{b}} \sum_{s=\frac{n+1}{2}}^{n-m}\left(\begin{array}{c}
n-m \\
s
\end{array}\right) q_{N B}^{s}\left(1-q_{N B}\right)^{n-m-s} \\
& +\sum_{s_{b}=k_{b}}^{m}\left(\begin{array}{c}
m \\
s_{b}
\end{array}\right) \widetilde{q}_{B}^{s_{b}}\left(1-\widetilde{q}_{B}\right)^{m-s_{b}} \sum_{s=\frac{n+1}{2}-m}^{n-m}\left(\begin{array}{c}
n-m \\
s
\end{array}\right) q_{N B}^{s}\left(1-q_{N B}\right)^{n-m-s}
\end{aligned}
$$

where $\widetilde{q}_{B}=\bar{q}-\left(\bar{q}-q_{B}\right) \exp (-T)$. The difference in utility levels is given by:

$$
\begin{aligned}
& \Pi_{B}(I N D)-\Pi_{B}(I N T)= \\
& =\sum_{s_{b}=1}^{m-k_{b}}\left(\left(\begin{array}{c}
m \\
s_{b}
\end{array}\right) \widetilde{q}_{B}^{s_{b}}\left(1-\widetilde{q}_{B}\right)^{m-s_{b}}\left(\sum_{s=\frac{n+1}{2}-s_{b}}^{\frac{n+1}{2}-1}\left(\begin{array}{c}
n-m \\
s
\end{array}\right) q_{N B}^{s}\left(1-q_{N B}\right)^{n-m-s}\right)\right) \\
& -\sum_{s_{b}=k_{b}}^{m-1}\left(\left(\begin{array}{c}
m \\
s_{b}
\end{array}\right) \widetilde{q}_{B}^{s_{b}}\left(1-\widetilde{q}_{B}\right)^{m-s_{b}}\left(\sum_{s=\frac{n+1}{2}-m}^{\frac{n+1}{2}-s_{b}-1}\left(\begin{array}{c}
n-m \\
s
\end{array}\right) q_{N B}^{s}\left(1-q_{N B}\right)^{n-m-s}\right)\right) \gtreqless 0
\end{aligned}
$$

The difference is indeterminate, as two effects are at play: for higher $s_{b}(1)$ the expression $\widetilde{q}_{B}^{s_{b}}\left(1-\widetilde{q}_{B}\right)^{m-s_{b}}$ increases, but (2) the sum $\sum_{s=\frac{n+1}{2}-m}^{\frac{n-1}{2}-s_{b}}\left(\begin{array}{c}n-m \\ s\end{array}\right) q_{N B}^{s}\left(1-q_{N B}\right)^{n-m-s}$ decreases while the sum $\sum_{s=\frac{n-1}{2}-s_{b}}^{\frac{n-1}{2}}\left(\begin{array}{c}n-m \\ s\end{array}\right) q_{N B}^{s}\left(1-q_{N B}\right)^{n-m-s}$ increases. The sign of the difference and therefore the choice of the optimal voting strategy depends on which effect dominates. Thus, it depends on the relation between the levels of board members' learned skills $\widetilde{q}_{B}$ and non-board members inherent skills $q_{N B}$. Only if the learned skills of board members are sufficiently high relative to the inherent skills of other committee members, ${ }^{30}$ the first effect dominates and the difference is negative, suggesting that interdependent voting is preferable. Otherwise, independent voting is superior, ${ }^{31}$ i.e.:

$$
\begin{aligned}
\Pi_{B}(I N D) & >\Pi_{B}(I N T) \Leftrightarrow \widetilde{q}_{B} \approx q_{N B} \Leftrightarrow\left(\bar{q}-q_{B}\right) \exp (-T) \approx\left(\bar{q}-q_{N B}\right) \\
& \Leftrightarrow\left(q_{B} \approx q_{N B} \cap T \rightarrow 0\right) \cup\left(q_{B} \approx q_{N B} \approx \bar{q}\right) \\
\Pi_{B}(I N D) & <\Pi_{B}(I N T) \Leftrightarrow \widetilde{q}_{B}>>q_{N B} \Leftrightarrow\left(\bar{q}-q_{N B}\right)>>\left(\bar{q}-q_{B}\right) \exp (-T) \\
& \Leftrightarrow\left(q_{B} \approx q_{N B} \cap T>>0\right) \cup\left(\left(\bar{q}-q_{N B}\right)>>\left(\bar{q}-q_{B}\right)\right)
\end{aligned}
$$

\footnotetext{
${ }^{30}$ This can be due to any of the following: an initial asymmetry in expertise or an abundance of time for discussions.

${ }^{31}$ Here a special case is the situation, when interdependent voting is inferior under symmetric inherent skills and no learning, discussed earlier in the literature (see, for example, Nitzan and Paroush, 1985, Ladha, 1992, or Ladha, 1995).
} 


\section{Case 2. Learning in both the informal meeting and the policy meeting}

In this case all committee members may have to choose between voting independently or interdependently. We will analyze the game backwards, starting with the decision of non-board committee members. If board members vote independently, non-board committee members vote independently as well. If board members present a common position, non-board members have the choice between obtaining the following utility levels: ${ }^{32}$

$$
\begin{aligned}
\Pi_{N B}(I N D)= & \sum_{s_{b}=m-k_{b}+1}^{k_{b}-1}\left(\left(\begin{array}{c}
m \\
s_{b}
\end{array}\right) \widetilde{q}_{B}^{s_{b}}\left(1-\widetilde{q}_{B}\right)^{m-s_{b}} \sum_{s=\frac{n+1}{2}-s_{b}}^{n-m}\left(\begin{array}{c}
n-m \\
s
\end{array}\right) \widetilde{q}_{N B}^{s}\left(1-\widetilde{q}_{N B}\right)^{n-m-s}\right) \\
& +\sum_{s_{b}=k_{b}}^{m}\left(\begin{array}{c}
m \\
s_{b}
\end{array}\right) \widetilde{q}_{B}^{m-s_{b}}\left(1-\widetilde{q}_{B}\right)^{s b} \sum_{s=\frac{n+1}{2}}^{n-m}\left(\begin{array}{c}
n-m \\
s
\end{array}\right) \widetilde{q}_{N B}^{s}\left(1-\widetilde{q}_{N B}\right)^{n-m-s} \\
& +\sum_{s_{b}=k_{b}}^{m}\left(\begin{array}{c}
m \\
s_{b}
\end{array}\right) \widetilde{q}_{B}^{s_{b}}\left(1-\widetilde{q}_{B}\right)^{m-s_{b}} \sum_{s=\frac{n+1}{2}-m}^{n-m}\left(\begin{array}{c}
n-m \\
s
\end{array}\right) \widetilde{q}_{N B}^{s}\left(1-\widetilde{q}_{N B}\right)^{n-m-s}
\end{aligned}
$$

and

$$
\begin{aligned}
\Pi_{N B}(I N T)= & \sum_{s_{b}=m-k_{b}+1}^{k_{b}-1}\left(\left(\begin{array}{c}
m \\
s_{b}
\end{array}\right) \widetilde{q}_{B}^{s_{b}}\left(1-\widetilde{q}_{B}\right)^{m-s_{b}} \sum_{s=\frac{n+1}{2}-s_{b}}^{n-m}\left(\begin{array}{c}
n-m \\
s
\end{array}\right) \widetilde{q}_{N B}^{s}\left(1-\widetilde{q}_{N B}\right)^{n-m-s}\right) \\
& +\sum_{s_{b}=k_{b}}^{m}\left(\begin{array}{c}
m \\
s_{b}
\end{array}\right) \widetilde{q}_{B}^{s_{b}}\left(1-\widetilde{q}_{B}\right)^{m-s_{b}}
\end{aligned}
$$

where $\widetilde{q}_{B}=\bar{q}-\left(\bar{q}-q_{B}\right) \exp (-T)$ and $\widetilde{q}_{N B}=\widetilde{\widetilde{q}}_{B}-\left(\widetilde{\widetilde{q}}_{B}-q_{N B}\right) \exp \left(-\frac{m}{n} T\right)$, $\widetilde{\widetilde{q}}_{B}=\bar{q}-\left(\bar{q}-q_{B}\right) \exp (-2 T) .^{33}$

The difference in the utility levels is given by:

$$
\begin{gathered}
\Pi_{N B}(I N D)-\Pi_{N B}(I N T)=\sum_{s_{b}=0}^{m-k_{b}}\left(\begin{array}{c}
m \\
s_{b}
\end{array}\right) \widetilde{q}_{B}^{s_{b}}\left(1-\widetilde{q}_{B}\right)^{m-s_{b}} \sum_{s=\frac{n+1}{2}}^{n-m}\left(\begin{array}{c}
n-m \\
s
\end{array}\right) \widetilde{q}_{N B}^{s}\left(1-\widetilde{q}_{N B}\right)^{n-m-s} \\
-\sum_{s_{b}=k_{b}}^{m}\left(\begin{array}{c}
m \\
s_{b}
\end{array}\right) \widetilde{q}_{B}^{s_{b}}\left(1-\widetilde{q}_{B}\right)^{m-s_{b}} \sum_{s=0}^{\frac{n-1}{2}-m}\left(\begin{array}{c}
n-m \\
s
\end{array}\right) \widetilde{q}_{N B}^{s}\left(1-\widetilde{q}_{N B}\right)^{n-m-s} \gtreqless 0
\end{gathered}
$$

\footnotetext{
${ }^{32}$ This choice is meaningful only if the board does not dominate the committee, i.e. only if $n-m \geq \frac{n+1}{2}$. Otherwise, the board's common position determines the outcome of the interest rate voting. As a result, in small committees, the payoffs of non-board committee members are equal: $\Pi(I N D)=\Pi(I N T)$.

${ }^{33}$ The formulas for $\widetilde{q}_{B}$ and $\widetilde{q}_{N B}$ are written out here to keep in mind two important facts: (1) board members have taken decision on their common position after learning time $T$, and (2) non-board members make their strategic choice after time $T$; however, their level of skills converges to the skills of board members attained after time $2 T$ (board members continue to learn from one another in the second stage of the decision making process).
} 
The difference is indeterminate since: (1) the sum $\sum_{s_{b}=k_{b}}^{m}\left(\begin{array}{c}m \\ s_{b}\end{array}\right) \widetilde{q}_{B}^{s_{b}}\left(1-\widetilde{q}_{B}\right)^{m-s_{b}}$ is larger than $\sum_{s_{b}=0}^{m-k_{b}}\left(\begin{array}{c}m \\ s_{b}\end{array}\right) \widetilde{q}_{B}^{s_{b}}\left(1-\widetilde{q}_{B}\right)^{m-s_{b}}$ for $\widetilde{q}_{B}>0.5$, but $(2)$ the sum $\sum_{s=\frac{n+1}{2}}^{n-m}\left(\begin{array}{c}n-m \\ s\end{array}\right) \widetilde{q}_{N B}^{s}\left(1-\widetilde{q}_{N B}\right)^{n-m-s}$ is larger than $\sum_{s=0}^{\frac{n-1}{2}-m}\left(\begin{array}{c}n-m \\ s\end{array}\right) \widetilde{q}_{N B}^{s}\left(1-\widetilde{q}_{N B}\right)^{n-m-s}$. Again the sign of the difference and therefore the choice of the optimal voting strategy depends on the dominating effect, i.e. on the relation between skill levels:

$$
\begin{aligned}
\Pi_{N B}(I N D) & >\Pi_{N B}(I N T) \Leftrightarrow \widetilde{q}_{B} \approx \widetilde{q}_{N B} \\
& \Leftrightarrow\left(q_{B} \approx q_{N B} \cap T \approx 0\right) \cup\left(q_{B} \approx q_{N B} \approx \bar{q}\right) \\
\Pi_{N B}(I N D) & <\Pi_{N B}(I N T) \Leftrightarrow \widetilde{q}_{B}>>\widetilde{q}_{N B} \\
& \Leftrightarrow\left(\left(\bar{q}-q_{N B}\right)>>\left(\bar{q}-q_{B}\right)\right) \cup\left(q_{B} \approx q_{N B} \cap T>>0 \cap \frac{m}{n} \rightarrow 0\right)
\end{aligned}
$$

If $\Pi_{N B}(I N D)>\Pi_{N B}(I N T)$, that is if non-board members have no incentives to forego their private expertise and to vote interdependently, then board members face a similar choice to the one in the case with limited interaction. Under the same conditions, which make non-board members vote independently, board members will vote independently as well.

If non-board members are likely to choose to follow the common position of the board, then the choice of board members becomes: obtain the decision accuracy:

$$
\Pi_{B}(I N D)=\sum_{s_{b}=0}^{m}\left(\left(\begin{array}{c}
m \\
s_{b}
\end{array}\right) \widetilde{q}_{B}^{s_{b}}\left(1-\widetilde{q}_{B}\right)^{m-s_{b}} \sum_{s=\frac{n+1}{2}-s_{b}}^{n-m}\left(\begin{array}{c}
n-m \\
s
\end{array}\right) \widetilde{q}_{N B}^{s}\left(1-\widetilde{q}_{N B}\right)^{n-m-s}\right)
$$

or:

$$
\begin{aligned}
\Pi_{B}(I N T)= & \sum_{s_{b}=m-k_{b}+1}^{k_{b}-1}\left(\left(\begin{array}{c}
m \\
s_{b}
\end{array}\right) \widetilde{q}_{B}^{s_{b}}\left(1-\widetilde{q}_{B}\right)^{m-s_{b}} \sum_{s=\frac{n+1}{2}-s_{b}}^{n-m}\left(\begin{array}{c}
n-m \\
s
\end{array}\right) \widetilde{q}_{N B}^{s}\left(1-\widetilde{q}_{N B}\right)^{n-m-s}\right) \\
& +\sum_{s_{b}=k_{b}}^{m}\left(\begin{array}{l}
m \\
s_{b}
\end{array}\right) \widetilde{q}_{B}^{s_{b}}\left(1-\widetilde{q}_{B}\right)^{m-s_{b}}
\end{aligned}
$$

Under conditions requiring non-board members to forego their own expertise, board members will choose to vote interdependently as well, since then the 
difference:

$$
\begin{gathered}
\Pi_{B}(I N D)-\Pi_{B}(I N T)= \\
=\sum_{s_{b}=0}^{m-k_{b}}\left(\left(\begin{array}{c}
m \\
s_{b}
\end{array}\right) \widetilde{q}_{B}^{s_{b}}\left(1-\widetilde{q}_{B}\right)^{m-s_{b}} \sum_{s=\frac{n+1}{2}-s_{b}}^{n-m}\left(\begin{array}{c}
n-m \\
s
\end{array}\right) \widetilde{q}_{N B}^{s}\left(1-\widetilde{q}_{N B}\right)^{n-m-s}\right) \\
-\sum_{s_{b}=k_{b}}^{m}\left(\left(\begin{array}{c}
m \\
s_{b}
\end{array}\right) \widetilde{q}_{B}^{s_{b}}\left(1-\widetilde{q}_{B}\right)^{m-s_{b}} \sum_{s=0}^{\frac{n-1}{2}-s_{b}}\left(\begin{array}{c}
n-m \\
s
\end{array}\right) \widetilde{q}_{N B}^{s}\left(1-\widetilde{q}_{N B}\right)^{n-m-s}\right)
\end{gathered}
$$

is likely to be negative.

We therefore conclude that interdependent voting requires the following condition to be met: $\widetilde{q}_{B}>>\widetilde{q}_{N B}$. However, as we argue in the main text, this is not likely to be the case in the real-life. Q.E.D. 